\title{
Awareness on Heart Diseases among Bangladesh Army Personnel
}

\author{
Islam SS ${ }^{1}$, Rahman $\mathrm{MF}^{2}$, Huda MS 3 , Kabir SMH ${ }^{4}$, Hamid MA $^{5}$ \\ DOI:https://doi.org/10.3329/jafmc.v16i2.55298
}

\begin{abstract}
Introduction: Heart diseases are global public health problem. In $2015,14.31 \%$ of total death in Bangladesh was due to coronary heart disease. Moreover in 2016, 2(two) recruits and 1(one) officer of Bangladesh army encountered sudden death due to cardiac arrest.
\end{abstract}

Objective: To ascertain the level of knowledge, awareness and health practice regarding the threat of cardiovascular diseases among Bangladesh Army personnel.

Materials and Methods: This cross-sectional observational study was conducted among 242 members of Bangladesh Army in different training centers and school under Army training and doctrine command (ARTDOC), units of 19 infantry division, Battle group of ARTDOC and Head quarter (HQ) ARTDOC, from February to July 2017.

Results: Among the respondents, $56.2 \%, 45 \%$ and $44.6 \%$ respectively mentioned tobacco smoking, obesity and sedentary life style are the causes of heart disease and $62 \%, 42 \%, 31 \%, 10 \%$ and $2 \%$ mentioned that chest pain, shortness of breathing, sweating, radiating pain in jaw and extremity and snoring-sleep apnea are the symptoms and signs of heart disease.

Conclusion: From the study it was revealed that, majority of the respondents had poor level of knowledge on awareness of heart disease. Adequate effort may be taken to increase the awareness by expert professionals and social media.

Key-words: Awareness, Knowledge, Cardio vascular diseases, Army personnel.

\section{Introduction}

Cardiovascular disease is the most frequent cause of adult death in all parts of the world. In the developed countries the incidence of ischemic heart disease has been falling for the last two or three decades, but it is rising in Eastern Europe and Asia ${ }^{1}$. Heart attacks are mainly caused by a blockage that prevents blood from flowing to the heart ${ }^{2}$. The most important behavioral risk factors of heart disease are unhealthy diet, physical inactivity, tobacco use and harmful use of alcohol. The effects of behavioral risk factors may show up in individuals as raised blood pressure, raised blood glucose, raised blood lipids, over weight and obesity ${ }^{3}$. It is estimated that $90 \%$ of heart disease is preventable. Symptoms of heart attack include pain or discomfort in the center of the chest, pain or discomfort in the arms, the left shoulder, elbows, jaw or back ${ }^{4}$.

Heart diseases are the leading cause of death globally. Bangladeshies have higher CAD mortality and higher stroke mortality than Europe ${ }^{5}$. In Bangladesh Army, non-communicable disease or life style diseases are alarmingly showing an upward trend. Bangladesh Army is always at risk due to unavoidable stress of Army life. In 2016, total death cases in army were 64 where $31 \%$ cases were resulted from cardiovascular diseases ${ }^{6}$. The study was intended to ascertain the awareness on heart disease among the army persons with a view to reduce the incident of sudden death. Few perspectives were considered like the knowledge about cause, sign and symptoms, risk factors, prevention and control of heart disease and other associated factors. Association of awareness on heart disease with age, length of service, rank, level of education etc. also considered.

\section{Materials and Methods}

Persons serving in different training centers and school under ARTDOC, units of 19 infantry division, Battle group of ARTDOC and HQ ARTDOC irrespective of sex and rank below Colonel were the study population. It was a descriptive cross sectional study where the study area was selected purposively for the research. The study was conducted in a period of 6 months starting from February 2017 to July 2017. 242 persons were interviewed face to face by using semi structured questionnaire. After collection of data they were checked, verified and edited and then tabulated. Statistical analysis were done by SPSS v 20.0. The level of awareness on heart disease was assured by arbitrarily given score ' 1 ' for yes and ' 0 ' for no according to Cornell medical index (CMI)?. The respondents' awareness on heart disease was categorized as good level (score $>80 \%$ ), fair level $>50 \%$ to $<80 \%$, and poor level $<50 \%$. The total score was 242 .

\section{Results}

Figure 1 shows that the mean age of respondents was $36 \pm 8.5$ years ranging from $<25$ years to $>50$ years. Highest number $65(26.9 \%)$ of the respondents were in age group 40-45 years followed by $46(19.2 \%)$ in the age group 35-40. Out of 242

1. Col Sheikh Shahidul Islam, MBBS, MPH, MPhil, Contingent Commander, BANMED-6, Central Africaln Republic (CAR) (E-mail: shahid8bmtc@gmail.com) 2. Maj Gen Md Fashiur Rahman, ndc, SPP, MBBS, MPH, LLB, FCGP, MBA, MSS, PhD fellow, DGMS, Bangladesh Armed Forces 3. Brig Gen Muhammad Shams-ul-Huda, ndc, afwc, PSC, Chief of Doctrine Division, ARTDOC, Bangladesh Army 4. Brig Gen SM Humayan Kabir, MBBS, MPH, MPhil, Director, Chattogram Medical College, Chattogram 5. Lt Col Md Abdul Hamid, MBBS, MPH, Deputy Contingent Commander, BANMED-6, Central African Republic (CAR). 
respondents, within the age range of 40-45 yrs(40\%), 45-50 yrs(20\%), 35-40 yrs(20\%), 30-35 yrs(14\%) and 25-30 yrs(7\%) respectively found to have good knowledge on heart disease

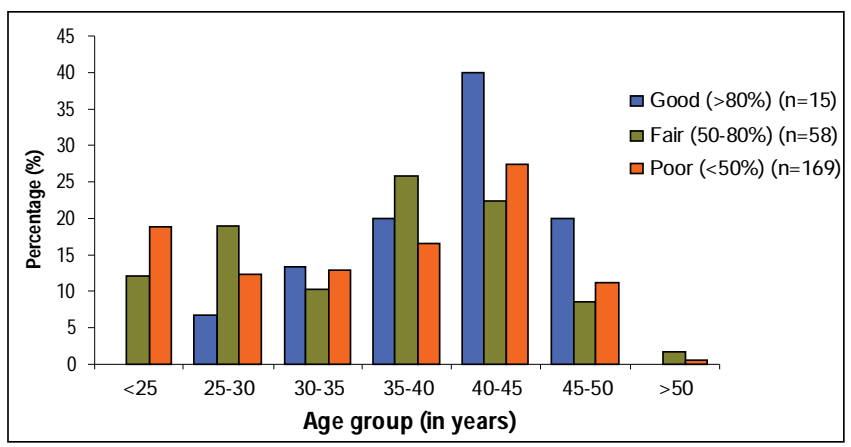

Figure-1: Distribution of respondents by age group and knowledge of heart diseases $(n=242)$

Out of 242 respondents about $62 \%, 42 \%, 31 \%, 11.5 \%, 10 \%$ and $2 \%$ could correctly mention that chest pain, shortness of breath, sweating, radiating pain in jaw and extremity and snoring-sleep apnea respectively are the sign and symptoms of heart disease, whereas the remaining respondents had no knowledge on the sign and symptoms of heart disease (Figure-2).

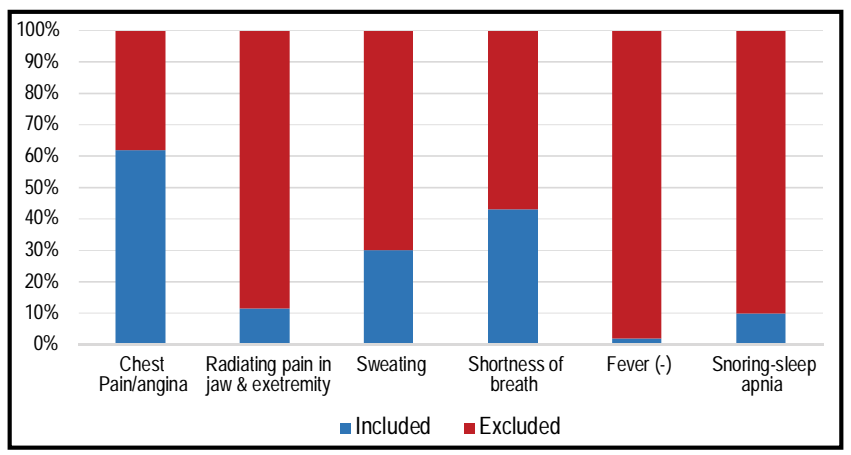

Figure-2: Knowledge on sign and symptom of heart disease $(n=242)$

Among the respondents, SSC and HSC qualified were found to be almost equal $(36.4 \%$ and $32.6 \%)$ where the percentage of graduate, postgraduate and class eight pass were $18.6 \%, 6.2 \%$, 5.4 , others $0.8 \%$ respectively. Among the respondents, $\mathrm{HSC}(33 \%)$, Graduates (26\%), SSC(20\%), Postgraduates(13\%) and Class Eight(7\%) respectively found to have good knowledge on heart disease whereas, others having various education level were found to have fair and poor knowledge on heart disease (Figure-3)

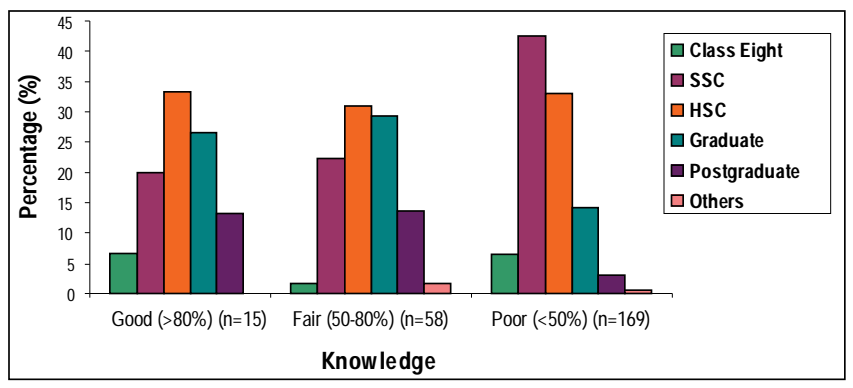

Figure-3: Association of knowledge about heart disease with education level $(n=242)$
Table-I shows that out of 242 respondents $42(17.4 \%), 5(2.1 \%)$, $44(18.2 \%), \quad 54(22.30 \%), \quad 109(45 \%), \quad 108(44.6 \%), 136(56.2 \%)$, $50(20.7 \%), 3(1.2 \%)$ could correctly mention that age, sex, family history, Diabetes Mellitus, obesity, sedentary life style, tobacco smoking, high cholesterol level are the contributory factors respectetively whereas the remaining number of the respondents could not correctly mention the cause of heart disease.

Table-I: Distribution of respondents by knowledge on cause of heart disease $(n=242)$

\begin{tabular}{|l|c|c|c|c|c|c|}
\hline \multirow{2}{*}{ Variables } & \multicolumn{2}{|c|}{ Included } & \multicolumn{2}{c|}{ Excluded } & \multicolumn{2}{c|}{ Total } \\
\cline { 2 - 8 } & N & Percent & N & Percent & N & Percent \\
\hline Age & 42 & 17.40 & 200 & 82.60 & 242 & 100.00 \\
\hline Sex & 5 & 2.10 & 237 & 97.90 & 242 & 100.00 \\
\hline Family history & 44 & 18.20 & 198 & 81.80 & 242 & 100.00 \\
\hline DM & 54 & 22.30 & 188 & 77.70 & 242 & 100.00 \\
\hline Obesity & 109 & 45.00 & 133 & 55.00 & 242 & 100.00 \\
\hline Sedentary Life style & 108 & 44.60 & 134 & 55.40 & 242 & 100.00 \\
\hline Tobaco smoking & 136 & 56.20 & 106 & 43.80 & 242 & 100.00 \\
\hline Highcholesterol level of blood & 50 & 20.70 & 192 & 79.30 & 242 & 100.00 \\
\hline Others & 3 & 1.20 & 239 & 98.80 & 242 & 100.00 \\
\hline
\end{tabular}

Out of 242 respondents, highest number was $61(25 \%)$ from the rank of soldier followed by 42(17.4\%), 40(16.5\%), 30(12.3\%), 20 (8.3\%), 19(7.8\%), 11(4.5\%), 6(2.4\%), 5(2.1\%), 4(1.6\%), 2(0.8\%), $1(0.4 \%)$ from Surgent, Warrant officer, Major, Senior Warrant Officer, Corporal, Lance Corporal, Captain, Colonel, Master of Warrant officer and Lieutenant respectively. Data were expressed as frequency and percentage, $P$ value reached from Chi-square test, significant. Good and fair level of knowledge-Major, poor level of knowledge-soldier (Table-II).

Table-II: Association of knowledge on cause of heart disease in different rank of Army ( $n=242)$

\begin{tabular}{|c|c|c|c|c|c|c|c|}
\hline \multirow{3}{*}{ Rank } & \multicolumn{6}{|c|}{ Knowledge on causes of heart disease } & \multirow{3}{*}{$P$ value } \\
\hline & \multicolumn{2}{|c|}{ Good } & \multicolumn{2}{|c|}{ Fair } & \multicolumn{2}{|c|}{ Poor } & \\
\hline & $\mathbf{n}$ & $\%$ & $\mathrm{n}$ & $\%$ & $\mathrm{n}$ & $\%$ & \\
\hline 2Lt & 0 & 0.0 & 0 & 0.0 & 1 & 0.5 & \\
\hline Capt & 0 & 0.0 & 1 & 3.3 & 5 & 2.5 & \\
\hline Col & 0 & 0.0 & 0 & 0.0 & 1 & 0.5 & \\
\hline Cpl & 0 & 0.0 & 2 & 6.7 & 17 & 8.4 & \\
\hline Lcpl & 0 & 0.0 & 1 & 3.3 & 10 & 4.9 & \\
\hline Lt & 0 & 0.0 & 0 & 0.0 & 4 & 2.0 & \\
\hline Lt Col & 0 & 0.0 & 3 & 100 & 2 & 1.0 & $0.073^{\mathrm{nS}}$ \\
\hline Maj & 4 & 44.4 & 7 & 23.3 & 19 & 9.4 & \\
\hline MWO & 0 & 0.0 & 0 & 0.0 & 2 & 1.0 & \\
\hline Sgt & 2 & 22.2 & 6 & 20.0 & 34 & 16.7 & \\
\hline Snk & 1 & 11.1 & 3 & 10.0 & 57 & 28.1 & \\
\hline Swo & 2 & 22.2 & 1 & 3.3 & 17 & 8.4 & \\
\hline Wo & 0 & 0 & 6 & 20.0 & 34 & 16.7 & \\
\hline Total & 9 & 100.0 & 30 & 100.0 & 203 & 100.0 & \\
\hline
\end{tabular}


Table-III reveals that out of 242 respondents 138(57\%), 63(26\%), 146(60.3\%) could correctly mention that, Diet control, Drug and Regular exercise respectively are the contributory factors in controlling diabetes Mellitus whereas, the remaining number of the respondents could not correctly mention the contributory factors to control Diabetes Mellitus.

Table-III: Respondents' Knowledge on control of Diabetes Mellitus $(n=242)$

\begin{tabular}{|l|c|c|c|c|c|c|}
\hline \multirow{2}{*}{} & \multicolumn{2}{|c|}{ Included } & \multicolumn{2}{c|}{ Excluded } & \multicolumn{2}{c|}{ Total } \\
\cline { 2 - 7 } & N & Percent & N & Percent & N & Percent \\
\hline Diet & $\begin{array}{c}13 \\
8\end{array}$ & 57.00 & 104 & 43.00 & 242 & 100 \\
\hline Drug & 63 & 26.00 & 179 & 74.00 & 242 & 100 \\
\hline Regular Exercise & $\begin{array}{c}14 \\
6\end{array}$ & 60.30 & 96 & 39.70 & 242 & 100 \\
\hline Rest \& recreation (-) & 20 & 8.30 & 222 & 91.70 & 242 & 100 \\
\hline
\end{tabular}

Respondents, having 10-15 years of service mostly had good level of knowledge about factors affecting heart diseases, fair and poor level level of knowledge was found mostly in 20-25 years long service holders (Table-IV)

Table-IV: Association of knowledge on risk factor of heart disease and duration of service $(n=242)$

\begin{tabular}{|c|c|c|c|c|c|c|c|}
\hline \multirow{3}{*}{$\begin{array}{c}\text { Duration } \\
\text { of } \\
\text { service }\end{array}$} & \multicolumn{6}{|c|}{ Knowledge onrisk factors of heart disease } & \multirow{3}{*}{ P value } \\
\hline & \multicolumn{2}{|c|}{ Good } & \multicolumn{2}{|c|}{ Fair } & \multicolumn{2}{|c|}{ Poor } & \\
\hline & $\mathrm{n}$ & $\%$ & $\mathrm{n}$ & $\%$ & $\mathrm{n}$ & $\%$ & \\
\hline$<5$ & 0 & 0.0 & 6 & 8.6 & 29 & 17.8 & \multirow{8}{*}{$0.25 \mathrm{gns}^{\mathrm{ns}}$} \\
\hline 5-10 & 2 & 22.2 & 6 & 8.6 & 9 & 5.5 & \\
\hline 10-15 & 3 & 33.3 & 10 & 14.3 & 28 & 17.2 & \\
\hline $15-20$ & 2 & 22.2 & 7 & 10.0 & 20 & 12.3 & \\
\hline $20-25$ & 1 & 11.1 & 27 & 38.6 & 44 & 27.0 & \\
\hline $25-30$ & 1 & 11.1 & 13 & 18.6 & 29 & 17.8 & \\
\hline$>30$ & 0 & 0.0 & 1 & 1.4 & 4 & 2.5 & \\
\hline Total & 9 & 100.0 & 70 & 100.0 & 163 & 100.0 & \\
\hline
\end{tabular}

\section{Discussion}

The respondents were exposed to strenuous duties and heavy physical exercise while providing training to the military students and at the same time they were involved in overall management of difficulties faced by the cadets, trainee officers and newly appointed recruits. During heavy physical activity, the trainees are susceptible to develop various health related problems which sometimes turns into fatal incidents and affects the moral of the troops. The members of Bangladesh Army belong to different socioeconomic classes according to their family background found in this study?.

Out of 242 respondents, 47 (forty-seven) were officers of different ranks, 60(sixty) Junior Commissioned Officers, 61(sixty one)
Noncommissioned officers and 72(seventy two) Lance Corporal and sainik participated in the subject survey.

In 2016, there were few fatal incidents took place at Bangladesh Infantry Regimental Centre and School, Rajshahi and Artillery Training Centre and School, Chittagong where 02(two) of the recruits died suddenly during morning physical training in the field which created a panic among the army personnel. Due to some other similar fatal incidents, the present study on awareness about heart disease has become a dire need to reduce the risk of sudden death due to heart disease in Army. It is obvious that, increased awareness can play a vital role to reduce the lethal outcome of heart disease. To asses and determine the level of awareness among the army persons, few parameters have been considered like age, arms and services, rank, duration of service of the individual, level of education, knowledge on risk factor and specially knowledge on cause, sign and symptoms of heart disease. The mean age of the respondents was $36 \pm 8.5$ years ranging from $<25$ years to $>50$ years. The educational level of the respondents in this study were found to be ranged from class eight passed to postgraduate which is almost similar to the findings of study conducted by Angosta $A D$ et $a l^{8}$. The age differenc of the respondents of this two studies may be due to specific entry of age in Bangladesh Army and also the racial variation between the two study population.

In this study, it was evident that, majority of respondents had poor knowledge on cause of heart disease while mentioning age, sex, family history, DM, sedentary life style, obesity as contributing factors to heart disease while fair knowledge on tobacco smoking and high blood cholesterol level as cause of heart disease. Out of 242 respondents $42(17.4 \%), 5(2.1 \%), 44(18.2 \%), 54(22.3 \%)$, 109(45\%), 108(44.6\%), 136(56.2\%), 50(20.7\%), 3(1.2\%) could correctly mention that age, sex, family history, diabetes mellitus, obesity, sedentary life style, tobacco smoking, high cholesterol level are the contributory factors respectively whereas the remaining number of the respondents could not correctly mention the cause of heart disease. It was found that $66.5 \%$ and $59.5 \%$ of the respondents had fair knowledge on HTN and smoking respectively, whereas, the remaining of the respondents was found to have poor level of knowledge on other risk factors of heart disease. It was also evident from the present study that, $62 \%$ of the respondents mentioned correctly chest pain as the symptom of heart disease whereas rest of the respondents could not mention the sign and symptoms of heart disease correctly. In a similar study conducted by Khan S and Ali SA revealed low levels of awareness on heart disease and associated risk factors in Emirati women only9. Awareness level was highest in Dubai among all other emirates and 18-45 yrs of age group. Emirati women clearly lack the knowledge on severity and vulnerability to heart disease in the region that is essential to improve cardiovascular related heart disease. It was also evident from the present study that good level of knowledge is associated with age ranges from $40-45$ years having HSC level education. In a similar study conducted by Awad 
$\mathrm{A}$ and Al-Nafisi $\mathrm{H}$ among the Kuwaiti citizens found the knowledge on risk factors of Heart Disease among Kuwaiti citizens is moderate ${ }^{10}$. The commonest factors identified by over four-fifth participants were smoking, obesity, unhealthy diet and physical inactivity.

In this study it was found that, out of 242 respondents 57\% \& $60.3 \%$ had fair knowledge on control of DM by diet control \& regular exercise whereas $26 \%$ had poor knowledge on control of DM. In a similar study conducted by Mohammad NB et al in Malaysia showed that out of 100 respondents, only $38 \%$ could mention that $\mathrm{DM}$ is a risk factor for Heart Disease/CVD ${ }^{11}$. The fact behind the difference may be due to continuous health education among the persons of Bangladesh Army as prevailed.

In the present study, the level of awareness on heart disease among the persons of Bangladesh Army are in a good state among the officers whereas, fair and poor state are prevailing mostly among the troops, which need to be improved by taking adequate effort specially by adopting health education, motivation and supervision of healthy practices.

\section{Conclusion}

To ensure the optimal health of the persons serving in Bangladesh Army and especially to reduce the fatality caused by heart diseases, efforts to be taken to increase health awareness by holistic approach in coordination with the civil health sector. Basic health education, active participation of the electronic and print media have great role in creating awareness and dissemination of knowledge regarding any public health problem. Various stress reducing activities can be introduced in centers to lower the rate of fatal incidents. In this regard clinical psychologists may be appointed to evaluate the mental state of the trainees/recruits to avoid training related physical and mental injuries. To prevent heart disease regular physical exercise and adoption of routine healthy life and avoidance of fatty food may play vital role where increased awareness may save the persons prone to develop heart disease.

\section{References}

1. Walker BR, Colledge NR, Ralston S et al. Davidson's Principles and Practice of Medicine. 23rd ed. Elsevier, UK 2018:444-5, 1150-1.

2. Kumar, Abbas and Fausto. Robbins and Cortan's pathologic Basis of Disease. 8th ed. Elsevier, 2007:585.

3. Park K; Park's Textbook of Preventive and Social Medicine. 18th ed. Jabalpur India: M/s Banarasidas Bhanot 2005:285-93.

4. McGill Jr HC, Mc Mahan CA, Gidding SS. Preventing Heart disease in the 21st century: implication of the Pathobiological Determinants of Atherosclerosis in Youth (PDAY) study. Circulation. 2008; 117(9):1216-27.

5. Hoque A, Moinuddin S. Effect of Arterial Hypertension on Postoperative Mortality and Morbidity after Off-pump CABG Surgery. Cardiovascular Journal. 2017; 10(1):13-6.

6. Rahman M. Disease Wise Death State 2015. Annual Health Report Bangladesh army, 2015:3-16.

7. Huntley RR. The Cornell Medical Index Health Questionnaire as a Diagnostic Aid. North Carolina Medical Journal. 1960; 21:50-2.

8. Angosta AD, Spek KE. Assessment of heart disease knowledge and risk factors among first-generation Filipino Americans residing in Southern Nevada. Clinical Nursing Studies. 2014; 2:2. DOI:10.5430/CNS.V2N2P123

9. Khan S, Ali SA. Exploratory study into awareness of heart disease and health care seeking behavior among Emirati women . BMC Women's Health. 2017; 17(88):2-10.

10. Awad A and Al-Nafisi H. Public knowledge of cardiovascular disease and its risk factors in Kuwait: A cross-sectional survey. BMC public health. 2014; 14:1131.

11. Mohammad NB, Rahman NAA, Haque M et al. Knowledge, Attitude, and Practice Regarding the Risk of Cardiovascular Diseases in Patients Attending Outpatient Clinic in Kuantan, Malaysia. J Pharm Bioallied Sci. 2018; 10(1):7-14. 